\title{
Photoinduced hydrophilic property of zinc oxide thin films prepared by sol-gel dip coating method
}

\author{
P. NUMPUD, T. CHARINPANITKUL ${ }^{\dagger}$ and W. TANTHAPANICHAKOON*
}

Center of Excellence in Particle Technology, Department of Chemical Engineering, Faculty of Engineering, Chulalongkorn University, Bangkok 10330, Thailand

*National Nanotechnology Center, National Science and Technology Development Agency Thailand Science Park, Thailand

\begin{abstract}
$\mathrm{ZnO}$ thin films could be fabricated on soda lime glass substrates by sol-gel dip coating method. The thin films fabrication conditions were zinc acetate concentration of $0.10-0.50 \times 10^{3} \mathrm{~mol} / \mathrm{m}^{3}$, withdrawal speed of $0.5-1.5 \times 10^{-3} \mathrm{~m} / \mathrm{s}$ and calcination temperature of $500^{\circ} \mathrm{C}$. The film characteristics (roughness, transparency and photoinduced hydrophilicity) were characterized by atomic force microscopy, UV-vis spectrophotoscopy and contact angle analyzer, respectively. It was found that the decreasing withdrawal speed of the coated film using $0.10 \times 10^{3} \mathrm{~mol} / \mathrm{m}^{3}$ zinc precursor could result in a decrease in the film thickness and the film roughness, consequently leading to highly photoinduced hydrophilicity.
\end{abstract}

(c) 2008 The Ceramic Society of Japan. All rights reserved.

Key-words: Hydrophilic, Znc oxide, Sol-gel, Dip coating

[Received November 18, 2007; Accepted February 21, 2008]

1. Introduction

The hydrophilicity of substrate surface refers to a physical property that can transiently bond with water through hydrogen bonding, leading to spreading of water across the surface rather than remaining as droplets. Normally hydrophilicity could be achieved after UV irradiation to substrate surface coated with some specific semiconductor. This property could physically be indicated by water contact angle. A surface with water contact angle lower than $10^{\circ}$ is classified as highly hydrophilic surface while a highly hydrophobic surface will show water contact angle higher than $150^{\circ}$

Zinc Oxide $(\mathrm{ZnO})$ is of great interest due to its unique optical, electrical and photo-catalyst properties. ${ }^{1)^{-5)}} \mathrm{ZnO}$ thin film can be coated on glass or plastic substrate with excellent transparency, which will not obstruct the substrate optical visibility, and can provide photoinduced hydrophilic function. Sol-gel method is widely employed for preparing $\mathrm{ZnO}$ because of its simplicity, safety and low cost. Moreover, incorporation of dip coating method could simply provide a smooth thin film of $\mathrm{ZnO}$ on substrate with large area. Sun et al. ${ }^{2)}$ reported that UV irradiation can generate electron-hole pairs on substrate surface coated with $\mathrm{ZnO}$ and leads to hydrophilic property due to some of the holes reacting with lattice oxygen to produce surface oxygen vacancies. However, there is a remaining issue that preferential adsorption of water on the coated surface cannot last long and reversibly turns to its initial condition after storage in the dark. ${ }^{6)-9)}$

The main purpose of the present work was to investigate the photoinduced hydrophilic property of glass substrate coated with $\mathrm{ZnO}$ thin film which was prepared by sol-gel process incorporated with dip coating technique. The hydrophilic surface was characterized by AFM, contact angle measurement and UV-vis spectroscopy. The effect of withdrawal speed and precursor concentration on the transmit-

† Corresponding author: E-mail: ctawat@chula.ac.th tance of the $\mathrm{ZnO}$ thin film was consequently investigated for finding systematic means to improve preparation of highly hydrophilic coated glass substrate.

\section{Experimental}

Starting precursor was prepared using zinc acetate $(95 \%$ purity, $\mathrm{M}=219.49, \mathrm{Zn}\left(\mathrm{CH}_{3} \mathrm{COO}\right)_{2} .2 \mathrm{H}_{2} \mathrm{O}$, Ajax Chemfine Australia), absolute ethanol (99.99\% purity, $\mathrm{M}=46.07$, $\mathrm{CH}_{3} \mathrm{CH}_{2} \mathrm{OH}$, Merck), acetic acid (99.9\% purity, $\mathrm{M}=46.07$, $\mathrm{CH}_{3} \mathrm{COOH}$, Merck) and deionized water. The zinc acetate was dissolved in $0.05 \times 10^{-3} \mathrm{~m}^{3}$ of absolute ethanol at room temperature. Deionized water and acetic acid were respectively added to the mixture solution with molar ratio of $2: 1$ and $0.01: 1$ with respect to the zinc acetate molar concentration. Then the solution was subject to heating at $60^{\circ} \mathrm{C}$ with magnetic stirring for $3600 \mathrm{~s}$ until a transparent and homogeneous solution was obtained. The concentration of zinc acetate was varied from 0.10 to $0.50 \times 10^{3} \mathrm{~mol} / \mathrm{m}^{3}$. Then thin film was deposited on cleaned glass substrate $(0.25 \mathrm{~mm} \times$ $0.30 \mathrm{~mm} \times 0.01 \mathrm{~mm})$ by the dip coating technique, in which the glass was immersed into the precursor solution for a certain period of $30 \mathrm{~s}$ and then withdrawn from the solution with a different withdrawal speed $\left(0.5,1.0\right.$ or $1.5 \times 10^{-3} \mathrm{~m} /$ s) under ambient condition by a step motor. The coated film was calcined in air at a heating rate of $0.05^{\circ} \mathrm{C} / \mathrm{s}$ and held for $3600 \mathrm{~s}$ at $500^{\circ} \mathrm{C}$. A UV-A lamp (SAPHIT A.J.L. Supplies, Thailand) with emission wavelength in a range of 300-460 $\mathrm{nm}$ and output of $20 \mathrm{~W}$ is employed to irradiate each coated glass specimen in priori to water contact angle investigation. Optical transmission of the $\mathrm{ZnO}$ thin films were characterized by comparison with uncoated substrate using a PerkinElmer Lambda 650 UV-Vis spectrophotometer. The particle size, roughness and uniformity of $\mathrm{ZnO}$ constituting in the films were characterized by an atomic force microscopy (AFM). The hydrophilicity of the thin films was then examined by measuring the contact angle of water droplets by a contact angle meter. Water droplets with consistent volume of $0.012 \times 10^{-6} \mathrm{~m}^{3}$ were placed at five difference positions on 
(a)

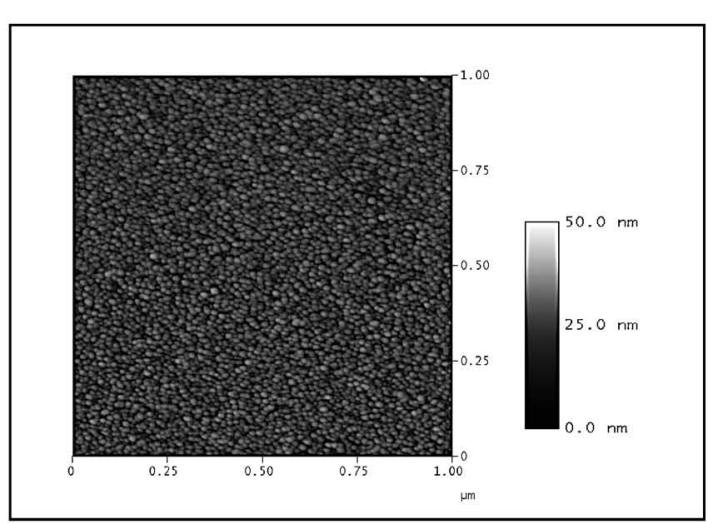

(b)

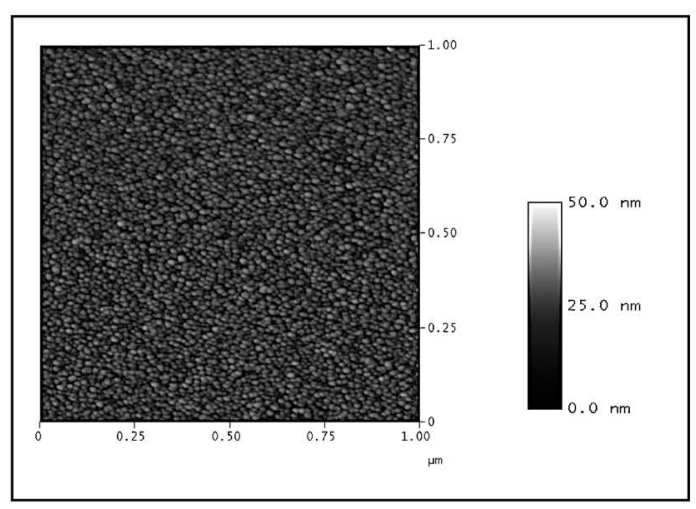

(c)

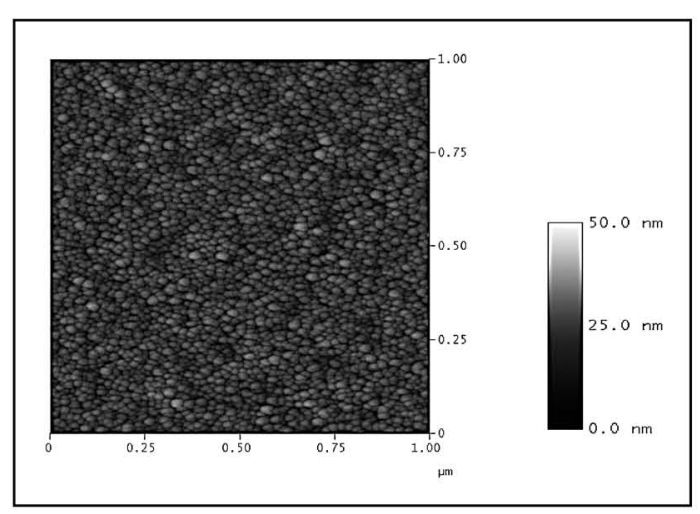

Fig. 1. AFM images of surface of $\mathrm{ZnO}$ coating films prepared from $0.10 \times 10^{3} \mathrm{~mol} / \mathrm{m}^{3}$ zinc acetate with different withdrawal speeds of (a) $0.5 \times 10^{-3} \mathrm{~m} / \mathrm{s}$, (b) $1.0 \times 10^{-3} \mathrm{~m} / \mathrm{s}$ and (c) $1.5 \times 10^{-3}$ $\mathrm{m} / \mathrm{s}$.

each coated substrate sample for measuring the contact angle.

\section{Results and discussion}

Figures 1a, b and c represent typical AFM images of the morphology of $\mathrm{ZnO}$ thin films prepared from $0.10 \times 10^{3}$ $\mathrm{mol} / \mathrm{m}^{3}$ zinc acetate with three different withdrawal speeds of $0.5,1.0$ and $1.5 \times 10^{-3} \mathrm{~m} / \mathrm{s}$, respectively. It could be clearly observed that the grain size depends on the withdrawal speed. The grain sizes of $\mathrm{ZnO}$ in the coated films prepared from the same zinc acetate concentration are 18.0, 19.5, 23.0
Table 1. Surface Roughness and Average Grain Size of $\mathrm{ZnO}$ thin Films with Different zinc Acetate Concentrations and Withdrawal Speeds

\begin{tabular}{cccc}
\hline $\begin{array}{l}\text { Zinc acetate } \\
\text { concentration } \\
\left(\times 10^{3} \mathrm{~mol} / \mathrm{m}^{3}\right)\end{array}$ & withdrawal speed & $\mathrm{R}_{\mathrm{rms}}$ & average grain size \\
\hline \multirow{2}{*}{0.10} & $\left(\times 10^{-3} \mathrm{~m} / \mathrm{s}\right)$ & $(\mathrm{nm})$ & $(\mathrm{nm})$ \\
& 0.5 & 2.1 & 18.0 \\
& 1.0 & 2.4 & 19.5 \\
0.25 & 1.5 & 2.2 & 23.0 \\
& 0.5 & 3.7 & 19.0 \\
0.50 & 1.0 & 3.2 & 25.5 \\
& 1.5 & 9.2 & 29.0 \\
& 0.5 & 4.3 & 22.5 \\
& 1.0 & 4.6 & 20.5 \\
& 1.5 & 5.5 & 26.0 \\
\hline
\end{tabular}

nm as shown in Fig. 1a, b, and c, respectively. The surface roughness and average grain size of the $\mathrm{ZnO}$ thin films with different zinc acetate concentration of $0.10,0.25,0.50 \times 10^{3}$ $\mathrm{mol} / \mathrm{m}^{3}$ and different withdrawal speed were also summarized in Table 1. It was found that with the highest concentration of $0.50 \times 10^{3} \mathrm{~mol} / \mathrm{m}^{3}$ the surface roughness mean square (rms) of the coated films increased from 4.3 to 5.5 $\mathrm{nm}$ when the glass substrates were withdrawal from the solution with the speed of 0.5 to $1.5 \times 10^{-3} \mathrm{~m} / \mathrm{s}$, respectively. The increase in film thickness which is subject to the withdrawal speed is attributed to competitive effects of gravitational and frictional viscous forces acting on the liquid coating film and evaporation of solvent. ${ }^{10)-12 \text { ) }}$

Figure 2 reveals the optical transmittance spectra of the $\mathrm{ZnO}$ films coated on glass substrates using zinc acetate concentration of 0.10 and $0.50 \times 10^{3} \mathrm{~mol} / \mathrm{m}^{3}$ with different withdrawal speed of $0.5,1.0$ and $1.5 \times 10^{-3} \mathrm{~m} / \mathrm{s}$. All of the fabricated films exhibited transmittance of above $90 \%$ with respect to the range of visible light $(400-700 \mathrm{~nm})$, pointing out the evidence of their superior transparency. Meanwhile, it could also be seen that all coated substrates exhibited remarkable ultraviolet absorption at around $380 \mathrm{~nm}$, which is attributed to the intrinsic band gap of $\mathrm{ZnO}$. Lee et al confirmed that $\mathrm{ZnO}$ fine particles synthesized by sol-gel method contain ionized oxygen vacancy which could emit photons with specific wavelength of $\sim 500 \mathrm{~nm}$ depending on their crystal structure. ${ }^{13)}$ In our investigation change of withdrawal speed provides an appreciable effect on the transmittance of the coating film because there was difference in the grain size of $\mathrm{ZnO}$ film on each substrate. With $0.10 \times 10^{3} \mathrm{~mol} / \mathrm{m}^{3}$ zinc acetate, substrates with thicker coating layer could somehow absorb ultraviolet spectra with higher intensity. This result is in good agreement with that of Berber et al even though they used spin coating technique to prepare the $\mathrm{ZnO}$ thin film. ${ }^{5}$ However, it is interesting that with $0.50 \times 10^{3}$ $\mathrm{mol} / \mathrm{m}^{3}$ zinc acetate, the different trend could be observed. Significantly low transmittance and transparency compared with those of $0.10 \times 10^{3} \mathrm{~mol} / \mathrm{m}^{3}$ zinc acetate would be attributed to the increasing crystallinity due to the higher concentration.

To examine the hydrophilicity of the coated glass substrates, average water contact angle is plotted against the UV irradiation time as shown in Fig. 3. When $0.10 \times 10^{3} \mathrm{~mol} / \mathrm{m}^{3}$ 

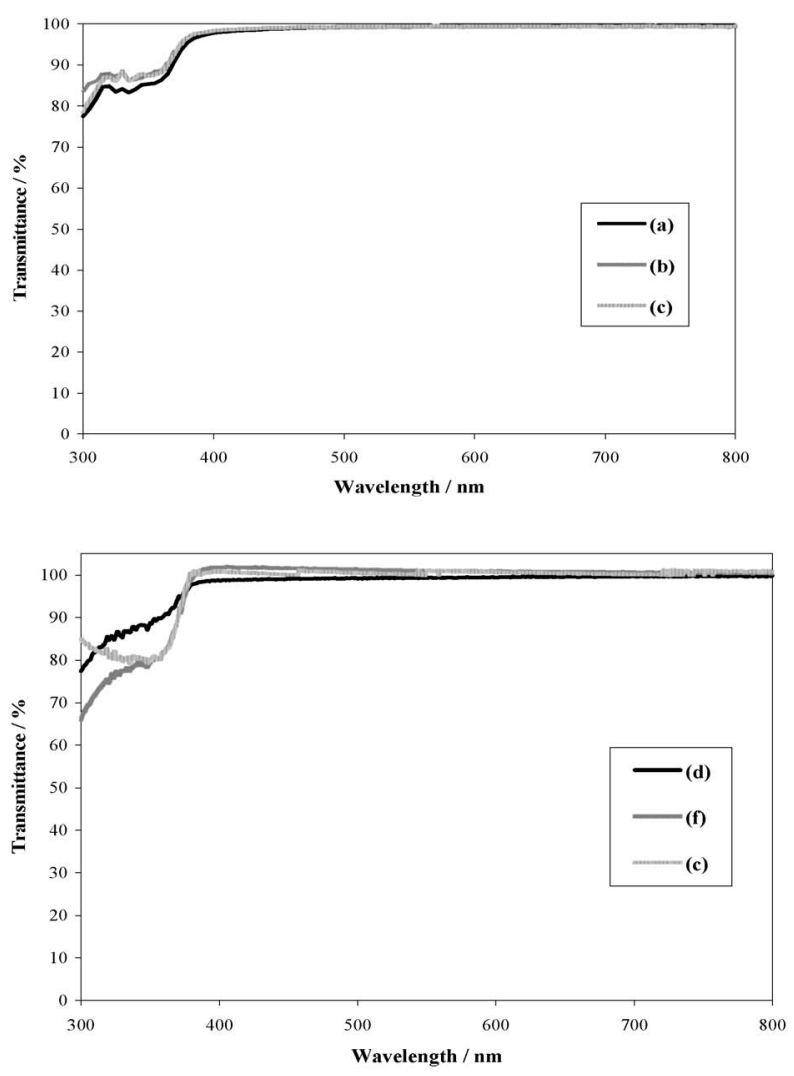

Fig. 2. Optical transmittance spectra of $\mathrm{ZnO}$ films prepared by dip coating. Above: in $0.10 \times 10^{3} \mathrm{~mol} / \mathrm{m}^{3}$ of zinc acetate with withdrawal speed of (a) $0.5 \times 10^{-3} \mathrm{~m} / \mathrm{s}$, (b) $1.0 \times 10^{-3} \mathrm{~m} / \mathrm{s}$ and (c) $1.5 \times$ $10^{-3} \mathrm{~m} / \mathrm{s}$, Below: in $0.50 \times 10^{3} \mathrm{~mol} / \mathrm{m}^{3}$ of zinc acetate with withdrawal speed of (d) $0.5 \times 10^{-3} \mathrm{~m} / \mathrm{s}$, (e) $1.0 \times 10^{-3} \mathrm{~m} / \mathrm{s}$ and (f) $1.5 \times 10^{-3} \mathrm{~m} / \mathrm{s}$

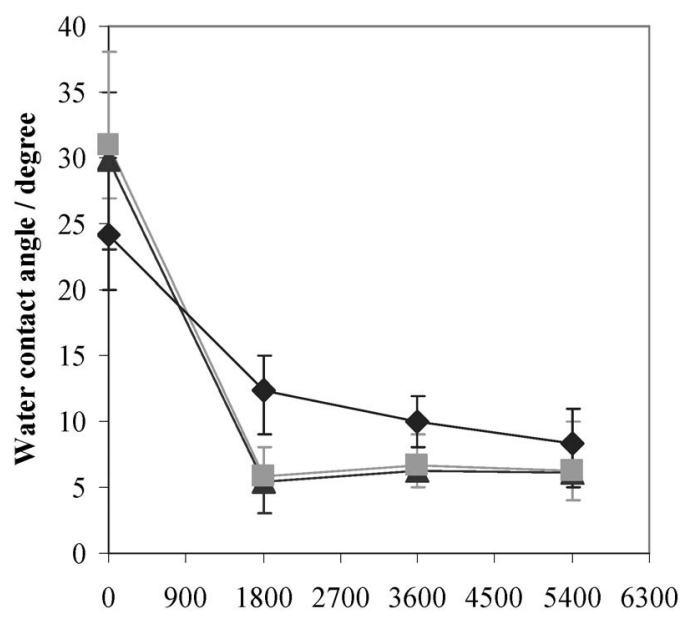

UV irradiation time / s

Fig. 3. Dependence of water contact angle of $\mathrm{ZnO}$ films on UV irradiation time $\left(\boldsymbol{\Delta}\right.$; withdrawal speed $=0.5 \times 10^{-3} \mathrm{~m} / \mathrm{s}, \quad$; withdrawal speed $=1.0 \times 10^{-3} \mathrm{~m} / \mathrm{s}$ and $\boldsymbol{\text { ; }}$ withdrawal speed $=1.5 \times$ $\left.10^{-3} \mathrm{~m} / \mathrm{s}\right)$.

zinc acetate was prepared to coat on the glass substrate with different withdrawal speed of $0.5,1.0,1.5 \times 10^{-3} \mathrm{~m} / \mathrm{s}$, it

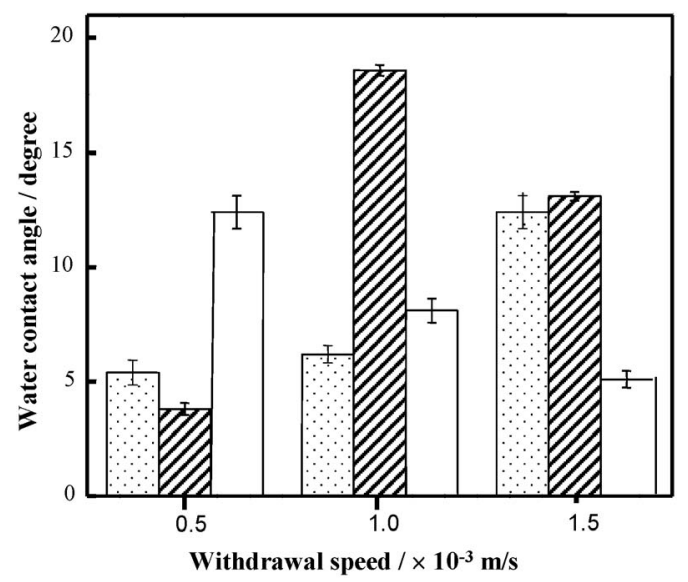

Fig. 4. Effect of precursor concentration on water contact angle of the coated film after UV irradiation for $1,800 \mathrm{~s}$ ( zinc acetate concentration $=0.10 \times 10^{3} \mathrm{~mol} / \mathrm{m}^{3}, \square$; zinc acetate concentration $=$ $0.25 \times 10^{3} \mathrm{~mol} / \mathrm{m}^{3}$ and $\square$; zinc acetate concentration $=0.50 \times 10^{3}$ $\left.\mathrm{mol} / \mathrm{m}^{3}\right)$.

could be observed that highly hydrophilic substrates with the water contact angle lower than $5^{\circ}$ could be obtained with UV irradiation for only $1800 \mathrm{~s}$. As the whole tendency, the longer the UV irradiation time was spent, the lower the water contact angle was achieved. Therefore, with the lowest withdrawal speed of $0.1 \times 10^{-3} \mathrm{~m} / \mathrm{s}$ the average water contact angle became significantly smaller. This would be attributable to the formation of thinner coating film containing smaller crystal which could adsorb more UV, resulting in higher hydrophilicity.

The effect of concentration of zinc acetate precursor on the water contact angle of the coating films is depicted in Fig. 4. As suggested by the experimental results shown in Fig. 3, all the substrates were prepared using different concentration of zinc acetate and different withdrawal speed with a constant UV irradiation time of $1,800 \mathrm{~s}$. However, the whole experimental results suggested the complicated dependence of the water contact angle on the film preparing parameters. When the $0.10 \times 10^{3} \mathrm{~mol} / \mathrm{m}^{3}$ zinc acetate precursor was employed the increasing withdrawal speed gave rise to worse hydrophilicity which was indicated by the higher water contact angle. This might be attributable to the increasing grain size and surface roughness, which could also be confirmed in Fig. 1. However, with the highest precursor concentration of $0.50 \times 10^{3} \mathrm{~mol} / \mathrm{m}^{3}$, opposite trend of the contact angle decreasing with the increasing withdrawal speed was observed. As already mentioned, the coated surface roughness increased with the increasing withdrawal speed. The hydrophilicity of the coated film would be controlled by both physical and chemical factors, which include change of surface roughness due to physical grain growth and change in surface polarity due to chemical adsorption. ${ }^{14)}$ The remaining issues would be how the hydrophilicity could be improved and kept longer after UV irradiation. Functional groups containing stronger hydrogen bonding would have to be taken into account to explain how dissociative adsorption of water molecules on the defective sites of UV-induced surface contributes to the formation of superior hydrophilic $\mathrm{ZnO}$ coated surface. 


\section{Conclusion}

With sol-gel dip coating method, zinc acetate could be used for preparing transparent $\mathrm{ZnO}$ film coated on glass substrates. All $\mathrm{ZnO}$ films coating on glass substrates could exhibit the excellent transparency with $90 \%$ visible light transmittances. It was also found that the $\mathrm{ZnO}$ grain size, surface roughness and hydrophilicity of the coating films were crucially affected by the precursor concentration and withdrawal speed. With UV irradiation for $1,800 \mathrm{~s}$, the highly hydrophilic $\mathrm{ZnO}$ thin films could be prepared. With the zinc acetate concentration of $0.10 \times 10^{3} \mathrm{~mol} / \mathrm{m}^{3}$, the lower withdrawal speed would lead to the thicker and rougher coating film with the water contact angle of $5^{\circ}$, which exhibited better hydroplicity.

Acknowledgement This work is a part of self-cleaning glass project which is supported by National Nanotechnology Center, National Science and Technology Development Agency. Also, partial support of Silver Jubilee Fund of Chulalongkorn University to Center of Excellence in Particle Technology is gratefully acknowledged.

\section{References}

1) G. Kaishu, Surface \& Coating Technology, 191, 155-160 (2005).

2) R. D. Sun, A. Nakajima, A. Fujishima, T. Watanabe and K.
Hashimoto, J. Phys. Chem. B, 105, 1984-1990 (2001).

3) C. Y. Kim, B. S. Kim, J. W. Choi, D. K. Choi and T. Y. Lim, J. Ceram. Soc. Japan, 112, 244-247 (2004).

4) X. Feng, L. Feng, M. Jin, J. Zhai, L. Jiang and D. Zhu, J/A/ $C / S$ communications (2003).

5) M. Berber, V. Bulto, R. KloB and H. Hahn, Scripta Material, 53, 547-551 (2005).

6) Q. Yu, H. Yang, W. Fu, L. Chang, C. Yu, R. Wei, K. Du, M. Li and G. Zou, Thin Solis Films, 515, 3840-3843 (2007).

7) T. Watanabe, A. Nakajima, R. Wang, M. Minabe., S. Koizumi, A. Fujishima and K. Hashimoto, Thin Solid Films, 351, 260-263 (1999).

8) Y. K. Du, Y. Q. Gan, P. Yang, F. Zhao, N. P. Hua and L. Jiang, Thin Solid Films, 491, 133-136 (2005).

9) S. Sharma, D. Singh, K. K. Saini, C. Kant, V. S harma, S. C. Jain and C. P. Sharma, Appl. Catal. A, 314, 40-46 (2006).

10) P. Yimsiri and M. R. Mackley, Chem. Eng. Sci., 61, 3496-3505 (2006).

11) C. J. Brinker and G. W. Scherer, Sol-gel Science, Academic Press New York (1990). pp. 790-799.

12) M. Ohyama, H. Kozuka and T. Yoko, Thin Solid Films, 306, 78-85 (1997).

13) G. H. Lee, N. Iwata, S. J. Kim and M. S. Kim, J. Ceram. Soc. Japan, 113, 64-66 (2005).

14) H. Kita, K. Osumi., T. Iizuka., M. Fukushima., K. Yoshida. and H. Hyuga, J. Ceram. Soc. Japan, 114, 599-602 (2006). 